\title{
KEBUTUHAN BAHAN BAKAR MINYAK PADA KAPAL PERIKANAN DI PELABUHAN PERIKANAN NUSANTARA PALABUHANRATU
}

\author{
Fuel Needs for Fishing Vessels at Palabuhanratu Nusantara Fishing Port
}

\author{
Oleh: \\ Daisy Rahma Rizal ${ }^{1}$, Fis Purwangka ${ }^{2 *}$, Mohammad Imron ${ }^{2}$, Sugeng Hari Wisudo ${ }^{2}$ \\ ${ }^{1}$ Program Studi Teknologi Perikanan Laut, Fakultas Perikanan dan Ilmu \\ Kelautan, Institut Pertanian Bogor, Jawa Barat, Indonesia \\ ${ }^{2}$ Departemen Pemanfaatan Sumberdaya Perikanan, Fakultas Perikanan dan \\ Ilmu Kelautan, Institut Pertanian Bogor, Jawa Barat, Indonesia \\ *Korespondensi penulis: fis@psp-ipb.org
}

\begin{abstract}
ABSTRAK
Fasilitas penyediaan Bahan Bakar Minyak (BBM) seperti Instalasi Bahan Bakar Minyak merupakan salah satu fasilitas fungsional pelabuhan perikanan. Namun nelayan masih kesulitan dalam mengakses BBM dengan harga normal dan stok yang tersedia tidak pasti. Tujuan penelitian ini yaitu mengidentifikasi jenis dan menghitung jumlah BBM yang dibutuhkan kapal perikanan di Pelabuhan Perikanan Nusantara (PPN) Palabuhanratu, mengidentifikasi jenis dan menghitung jumlah BBM yang disediakan penyalur BBM resmi, serta menentukan persediaan kebutuhan BBM dan merekomendasikan distribusi BBM yang baik bagi nelayan di PPN Palabuhanratu. Metode analisis yang digunakan yaitu analisis deskriptif dan analisis matematika sederhana. Hasil penelitian menunjukkan bahwa nelayan PPN Palabuhanratu membutuhkan BBM jenis solar dan bensin. Kebutuhan solar subsidi oleh kapal $\leq 30$ GT sebesar 568.041 liter selama satu tahun. Kebutuhan solar industri sebanyak 2.556 .000 liter dalam setahun. BBM jenis bensin yang dibutuhkan sebesar 676.202 liter dalam setahun. Rekomendasi untuk pendistribusian BBM yang lebih baik adalah melakukan penyederhanaan administasi perikanan agar mudah dalam mengakses BBM subsidi (satu identitas multifungsi), menggunakan perhitungan hasil penelitian untuk referensi kuota BBM dan membuka informasi akses kuota ketersediaan BBM untuk sektor perikanan pada setiap tempat pengisian BBM di sekitar PPN Palabuhanratu, dan membuat mekanisme terstruktur dan pengawasan ketat untuk pembelian BBM subsidi dan non-subsidi.
\end{abstract}

Kata kunci: BBM, bensin, kapal perikanan, PPN Palabuhanratu, solar

\begin{abstract}
Facilities for providing fuel, such as installation of fuel is one of the functional facilities of fishing ports. Fishermen still have difficulty in accessing fuel at normal prices and the available stock is uncertain. The purposes of this study are to identify the type and calculate the amount of fuel needed by fishing vessels at the NFP Palabuhanratu, identify the type and calculate the amount of fuel provided by official fuel distributors, and determine the supply of fuel needs and recommend a good distribution of fuel for fishermen in NFP Palabuhanratu. The analytical method used was descriptive analysis and simple mathematical analysis. The results showed that fishermen in NFP Palabuhanratu needed diesel and gasoline. The need for subsidized diesel by ships $\leq 30$ GT were 568,041 liters a year. Industrial diesel needs as much as 2,556,000 liters in a year. The type of gasoline needed were 676,202 liters in a year. Recommendations for better fuel distribution are simplifying fisheries administration so that it is easy to access subsidized fuel (one multifunctional identity), using research results calculations to reference fuel quotas and opening information on fuel availability quota access for the fisheries sector at each official fuel distributors around NFP Palabuhanratu, and create a structured mechanism and strict supervision for the purchase of subsidized and non-subsidized fuel.
\end{abstract}

Key words: fuel, gasoline, fishing vessels, NFP Palabuhanratu, diesel fuel 


\section{PENDAHULUAN}

Pelabuhan Perikanan (PP) sebagaimana diatur pada Undang-Undang Nomor 45 Tahun 2009 adalah tempat yang terdiri atas daratan dan perairan di sekitarnya dengan batas-batas tertentu sebagai tempat kegiatan pemerintahan dan kegiatan sistem bisnis perikanan yang digunakan sebagai tempat kapal perikanan bersandar, berlabuh, dan/atau bongkar muat ikan yang dilengkapi dengan fasilitas keselamatan pelayaran dan kegiatan penunjang perikanan. Menurut PERMEN KP No.08/2012 tentang Kepelabuhanan Perikanan menjelaskan bahwa fasilitas pelabuhan perikanan terbagi menjadi tiga, yaitu fasilitas pokok, fasilitas fungsional dan fasilitas penunjang. Fasilitas terkait penyediaan bahan bakar minyak (BBM) seperti instalasi bahan bakar minyak adalah salah satu fasilitas fungsional pelabuhan perikanan.

Bahan bakar minyak (BBM) termasuk komponen penting bagi aktivitas dalam usaha produksi ikan, khususnya untuk usaha perikanan kecil di Palabuhanratu (Luhur dan Sari 2012). Jumlah besar atau kecilnya pengeluaran untuk BBM dipengaruhi oleh berbagai faktor, antara lain seperti lama waktu melaut, jarak ke daerah penangkapan, ukuran kapal, jenis alat tangkap yang digunakan, mesin yang digunakan, dan bahan bakar yang digunakan (Rahardjo et al. 2011). Saat ini umumnya jarak nelayan menuju fishing ground semakin jauh, bukan semakin dekat. Sehingga jumlah BBM yang dibutuhkan akan semakin meningkat (Wijaya dan Saptanto 2014).

BBM jenis solar yang digunakan nelayan Pelabuhan Perikanan Nusantara (PPN) Palabuhanratu untuk melaut bersumber dari Solar Packed Dealer Nelayan (SPDN) yang dikelola oleh KUD Mina Mandiri Sinar Laut dan Stasiun Pengisian Bahan Bakar Nelayan (SPBN) yang dikelola oleh PT Mekar Tunas Raya Sejati (PPN Palabuhanratu 2020). Penyalur resmi BBM di Pelabuhan Perikanan Nusantara (PPN) Palabuhanratu mendapatkan suplai BBM dari pertamina atau instansi swasta nasional yang telah ditetapkan. Penyalur BBM selaku stakeholder utama dalam penelitian ini diharapkan memiliki suplai BBM yang sesuai dengan kebutuhan nelayan. Sehingga nelayan dapat diuntungkan dengan adanya BBM yang sesuai kebutuhan di dalam komplek pelabuhan karena jarak membeli BBM yang dekat dan harga BBM yang bersubsidi dapat mengurangi biaya operasional melaut.

Penelitian sebelumnya tentang hal serupa sudah dilakukan oleh Hallyzepta (2012), namun hanya menghasilkan jumlah kebutuhan solar bagi kapal pancing tonda. Oleh karena itu, penelitian lebih lanjut tentang kebutuhan BBM dengan kasus semua kapal penangkapan ikan di PPN Palabuhanratu diperlukan. Sehingga penelitian ini diharapkan dapat memberikan informasi jumlah BBM yang dibutuhkan nelayan dan pemanfaatannya, serta rekomendasi bagi pihak penyalur BBM, pelabuhan, Pertamina, dan Dinas Kelautan dan Perikanan Sukabumi mengenai kuota BBM.

Jumlah biaya operasional bergantung pada jumlah trip penangkapan, jauh dekatnya jarak nelayan melaut, dan banyaknya hasil tangkapan yang didapat. Jarak melaut yang semakin jauh akan memperbesar biaya operasi khususnya biaya perbekalan seperti biaya pembelian BBM, sebaliknya jika jarak semakin dekat akan menghemat biaya perbekalan (Sudrajat et al. 2014). Selama ini pengeluaran untuk pembelian BBM pada sektor usaha kecil di Palabuhanratu berkisar antara 40-60\% dari seluruh biaya operasional penangkapan ikan (Luhur dan Sari 2012). Terdapat nelayan atau pemilik kapal yang membeli BBM dengan harga lebih mahal daripada harga normalnya, hal ini menambah beban untuk biaya operasional melaut. Nelayan skala kecil khususnya nelayan $\leq 5$ GT membeli BBM dengan harga di atas harga normal. Para nelayan masih menghadapi kesulitan dalam menjangkau BBM dengan harga normal karena rata-rata jarak dari tempat pendaratan ikan (TPI) ke SPBN, SPDN dan Stasiun Pengisian Bahan Bakar Umum (SPBU) relatif jauh (Saptanto et al. 2016). Perkembangan terkini, nelayan kesulitan mendapatkan BBM bersubsidi dan non-subsidi. Bahkan banyak nelayan kecil terpaksa membeli BBM eceran dengan harga yang lebih tinggi (Kencana 2020). Berita mengenai beberapa stasiun pengisian bahan bakar minyak (SPBU) di wilayah Kabupaten Sukabumi khusunya wilayah Palabuhanratu sering mengalami kekurangan stok terutama pada jenis bensin premium dan solar subsidi, sehingga masyarakat kesulitan mendapatkan BBM bersubsidi (Fikri 2020).

Sehingga berdasarkan permasalahan tersebut, dibutuhkan informasi kebutuhan jumlah BBM pada pelabuhan agar nelayan dapat memperoleh BBM di dalam komplek pelabuhan yang memiliki jarak lebih dekat dengan kapal. Pola konsumsi BBM pada suatu wilayah pelabuhan dapat dipengaruhi oleh jumlah dan jenis armada penangkapan yang aktif beroperasi di pelabuhan tersebut (Shafira et al,. 2021). Berdasarkan hal tersebut, penelitian ini bertujuan menghitung jumlah dan mengidentifikasi jenis bahan bakar minyak (BBM) yang dibutuhkan kapal perikanan di PPN Palabuhanratu, mengidentifikasi jenis dan menghitung jumlah BBM yang disediakan penyalur BBM resmi di PPN Palabuhanratu, serta menentukan persediaan kebutuhan BBM dan merekomendasikan distribusi BBM yang baik bagi nelayan di PPN Palabuhanratu. 
Pencapaian terhadap tujuan tersebut dilakukan dengan pendekatan wawancara dan kuesioner kepada nelayan, petugas penyalur BBM, dan syahbandar untuk mendapatkan informasi mengenai BBM di PPN Palabuhanratu. Selain dengan wawancara, metode studi literatur diperlukan untuk mengetahui jumlah trip kapal.

\section{METODE PENELITIAN}

Metode pengumpulan data penelitian ini menggunakan metode studi literatur dan survei berupa wawancara langsung serta kuesinoner dengan melibatkan pihak peyalur resmi seperti SPDN dan SPBN, nelayan dan syahbandar PPN Palabuhanratu yang berhubungan dengan pengadaan dan pemanfaatan BBM di PPN Palabuhanratu. Metode pengumpulan data untuk tujuan pertama yaitu survei berupa wawancara dan kuesinoner kepada nelayan dan studi literatur yakni data statisik yang bersumber dari Badan Pusat Statistik PPN Palabuhanratu dan syahbandar. Penentuan responden pada tujuan pertama menggunakan teknik quota sampling.

Menurut data statistik syahbandar kapal di PPN Palabuhanratu tahun 2020 sebanyak 512 kapal dengan alat tangkap dominan pancing ulur, payang, bagan, tonda, trammel net, longline, dan jaring rampus. Sehingga tujuan pertama pada penelitian ini menggunakan sampel berdasarkan alat tangkap dominan tersebut. Dari data tersebut, perhitungan jumlah sampel yang dibutuhkan dalam penelitian ini dihitung menggunakan rumus Slovin (Ariola 2006):

$$
n=\frac{N}{1+N e^{2}}
$$

Keterangan:

$\mathrm{n}=$ Jumlah sampel

$\mathrm{N}=$ Jumlah seluruh anggota populasi

$\mathrm{e}=$ Batas toleransi kepercayaan (0.1)

Sehingga, didapatkan jumlah total responden sebanyak 84 responden dengan kuota pada masingmasing kelompok yaitu bagan 6 orang, pancing ulur 32 orang, payang 8 orang, pancing tonda 12 orang, jaring rampus 9 orang, trammel net 5 orang, dan rawai tuna 12 orang. Selain nelayan, sumber data yang digunakan yaitu frekuensi kapal keluar selama tahun 2020. Sedangkan jumlah trip untuk kapal longline dan kapal tonda bersumber dari data syahbandar berupa Surat Persetujuan Berlayar (SPB) Tahun 2020.

Teknik pengambilan data yang digunakan dalam tujuan kedua adalah purposive sampling. Target responden pada tujuan kedua adalah petugas penyalur resmi BBM di PPN Palabuhanratu yakni petugas SPDN dan SPBN. Responden harus memiliki kriteria tertentu, salah satu kriteria yang diperlukan adalah bekerja sebagai petugas harian dimana setiap jam kerja berada di tempat kerja atau kantor agar mengetahui pola konsumsi BBM nelayan. Metode pengumpulan data yang digunakan adalah survei dengan cara wawancara mendalam. Tujuan ketiga penelitian ini menggunakan data dari tujuan pertama dan kedua. Selanjutnya rekomendasi dihasilkan dari hasil penelitian ini.

Pengolahan data yang digunakan pada penelitian ini adalah perhitungan matematika sederhana. Data yang telah didapatkan akan ditabulasikan dan dibuat grafik dalam penampilannya. Data kebutuhan BBM dihitung dan ditampilkan berdasarkan alat tangkap yang digunakannya. Prosedur yang dilakukan dalam pengolahan data diuraikan sebagai berikut:

1) Mentabulasikan data penggunaan BBM hasil wawancara, yaitu data keperluan BBM setiap trip operasi penangkapan ikan dan jumlah trip dalam setiap bulannya. Jumlah BBM dan trip dibedakan berdasarkan musim penangkapan ikan yang berlangsung. Tercatat ada tiga musim penangkapan ikan, yaitu musim puncak penangkapan ikan, musim sedang, dan musim paceklik.

2) Menghitung rata-rata kebutuhan BBM berdasarkan hasil wawancara (data primer) menggunakan rumus (Hallyzepta 2011) yang dimodifikasi sesuai kebutuhan:

$$
\overline{B T h} \mathrm{a}=\frac{\sum_{m=1}^{X a} \sum_{n=1}^{3} \frac{s_{t n} \times t_{n}}{C_{m}}}{X_{a}}
$$

Keterangan:

$\overline{B T h}$ a $=$ Rata-rata kebutuhan BBM tahunan kapal dengan alat tangkap a (liter/unit)

$\mathrm{S}_{\mathrm{tn}} \quad=$ Jumlah kebutuhan BBM kapal a ke-m pada musim ke-n

$\mathrm{t}_{\mathrm{n}}=$ Jumlah trip kapal a ke-m pada musim ke-n 
$\mathrm{n} \quad=$ Musim penangkapan ikan ke-1 (musim puncak), ke-2 (musim sedang) dan ke-3 (musim paceklik)

$\mathrm{C}_{\mathrm{m}} \quad=$ Unit kapal ke-m

$\mathrm{m} \quad=1,2, \ldots \ldots, \mathrm{X}_{\mathrm{a}}$

$\mathrm{X}_{\mathrm{a}} \quad=$ Jumlah unit kapal a

a $\quad=$ Jenis alat tangkap

3) Menghitung jumlah kebutuhan BBM berdasarkan data statistik per kapal di bulan ke-z, yaitu dengan mengalikan antara jumlah kebutuhan BBM per trip di bulan ke-z dengan jumlah trip di bulan ke-z. Perhitungan ini diterapkan pada setiap kapal dengan alat tangkap yang berbeda. Adapun rumus yang digunakan dalam perhitungan sebagai berikut:

$$
S B_{z}=B T_{z} \times T_{z}
$$

Keterangan:

$\mathrm{SB}_{\mathrm{z}} \quad=$ Jumlah kebutuhan BBM per kapal di bulan ke-z (liter/unit)

$\mathrm{BT}_{\mathrm{z}} \quad=$ Jumlah kebutuhan BBM per trip kapal di bulan ke-z (liter/trip)

$\mathrm{T}_{\mathrm{z}} \quad=$ Jumlah trip per bulan

$\mathrm{z} \quad=1,2, \ldots \ldots \ldots, 12$

4) Menghitung jumlah kebutuhan BBM bulanan untuk seluruh kapal pada masing-masing alat tangkap. Jenis alat tangkap yang dihitung menggunakan rumus ini adalah pancing ulur, payang, bagan, tonda, trammel net, longline, dan jaring rampus. Tahapan pertama adalah mengalikan jumlah kebutuhan BBM per kapal di bulan ke-z dengan jumlah armada penangkapan ikan yang beroperasi di bulan ke-z dan selanjutnya ditotalkan untuk setiap bulan. Jumlah armada penangkapan ikan yang beroperasi setiap bulan diambil dari data Surat Persetujuan Berlayar. Tahapan kedua adalah membagi hasil total kebutuhan BBM tersebut dengan jumlah bulan operasi. Perhitungan ini dilakukan menggunakan rumus:

$$
\overline{B B_{a}}=\frac{\sum_{Z=1}^{12} B B_{Z} \times J K_{Z}}{12}
$$

Keterangan:

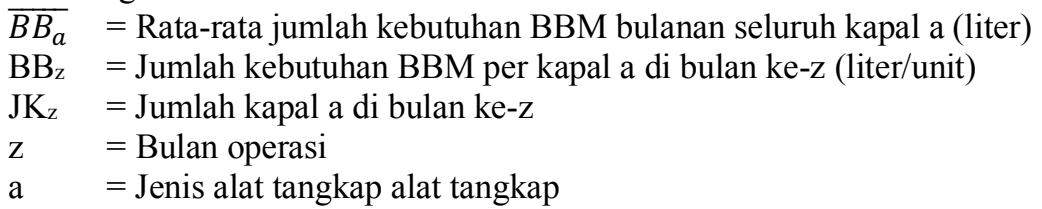

5) Menghitung jumlah kebutuhan BBM untuk seluruh kapal (tonda, trammel net, angkutan bagan, longline, jaring rampus, payang, pancing ulur) per tahun dengan cara menjumlahkan besaran kebutuhan BBM setiap bulan, mulai Januari hingga Desember.

6) Mengelompokkan jumlah BBM berdasarkan jenisnya. Kapal dengan alat tangkap tonda, longline $\leq 30$ GT, dan bagan dikelompokkan sebagai pengguna solar subsidi. Kapal dengan alat tangkap payang, jaring rampus, dan pancing ulur dikelompokkan sebagai pengguna bensin. Sedangkan kapal longline dikelompokkan sebagai pengguna solar non-subsidi.

7) Masing-masing kelompok BBM dibagi dengan besarnya jumlah pemasokan. Jumlah solar subsidi dan solar non-subsidi pada setiap bulan dan tahunnya dibagi dengan $16 \mathrm{KL}$, sehingga menghasilkan data jumlah penyuplaian mobil tangki pertamina dalam sebulan, setahun, dan rata-rata per bulan. Sedangkan untuk BBM jenis bensin, jumlah bensin dibagi dengan 30 liter, sehingga menghasilkan data jumlah penyuplaian jerigen dalam sebulan, setahun, dan rata-rata per bulan.

Data yang diperoleh dan diolah dengan program Microsoft Office Excel dan disajikan dalam bentuk tabel dan grafik, selanjutnya dianalisis secara deskriptif. Analisis deskriptif digunakan dalam menganalisa dan menjelaskan data dengan cara mendeskripsikan atau menggambarkan data-data kebutuhan BBM kapal perikanan di PPN Palabuhanratu yang telah dikumpulkan. Data yang dikumpulkan berasal dari kebutuhan peneliti sesuai dengan tujuan penelitian agar lebih mudah dipahami (Kartika et al. 2020). Tujuan pertama mendeskripsikan jumlah BBM pada masing-masing alat tangkap yang dikaitkan dengan musim penangkapan ikan. Selanjutnya pada tujuan kedua mendeskripsikan jumlah BBM yang disediakan penyalur BBM pada tiap bulannya. Tujuan ketiga mendeskripsikan jumlah penyuplaian yang dilakukan pertamina atau perusahaan swasta nasional serta merekomendasikan distribusi BBM yang baik. 


\section{HASIL DAN PEMBAHASAN}

\section{Kapal perikanan di PPN Palabuhanratu Tahun 2020}

Kapal perikanan di PPN Palabuhanratu terdiri dari beberapa jenis. Pengelompokkan berdasarkan jenis kapal terbagi menjadi sepuluh kelompok, diantaranya yaitu bagan, motor tempel, tonda, rampus, dogol, cash net, gillnet, purse seine, longline dan andon. Sedangkan jika berdasarkan alat penangkapan ikan meliputi bagan, pancing ulur, payang, bubu, pancing, jaring rampus/udang, jaring dogol, jalah jatuh berkapal, jaring gillnet, jaring purse seine, dan rawai tuna (PPN Palabuhanratu 2020). Perbedaan ukuran kapal mempengaruhi metode pengoperasian dari kapal itu sendiri, seperti jarak daerah penangkapan ikan yang dituju dan alat tangkap yang digunakan. Hal ini dikarenakan penggunaan daya mesin yang bebeda dan kemampuan kapal dalam menghadapi arus dan gelombang suatu perairan.

Daerah penangkapan ikan nelayan PPN Palabuhanratu berada di sekitar Teluk Palabuhanratu, Cisolok, Ujung Genteng, Binuangen, hingga jarak jauh meliputi perairan barat Sumatera, Pacitan, dan Samudera Hindia (Suherman et al. 2020). Menurut Ekaputra et al. (2019) dari 10 daerah penangkapan ikan (DPI) di perairan Palabuhanratu yang diidentifikasi, terdapat 2 DPI yang termasuk ke dalam kategori daerah penangkapan potensial yaitu pada titik koordinat 7' 9' 0 ' ' LS $106^{\circ} 25^{\prime} 12^{\prime \prime}$ BT dan $7^{\circ} 4^{\prime}$ ' 48' ' LS $106^{\circ} 27^{\prime}$ ' $36^{\prime \prime}$ BT. Terdapat 2 DPI yang termasuk kategori sedang yaitu $7^{\circ} 10^{\prime} 48^{\prime}$ ' $\mathrm{LS} 106^{\circ} 23^{\prime} 24^{\prime \prime}$ BT dan $7^{\circ} 7^{\prime}$ 48' LS 106 ${ }^{\circ}$ ' $98^{\prime}$ " BT. Berbagai mesin yang digunakan oleh kapal perikanan PPN Palabuhanratu umumnya memiliki umur teknis yang sama dengan umur kapal. Jenis-jenis mesin kapal di PPN Palabuhanratu yaitu mesin tempel berkekuatan 5,5 PK, 9 PK, 15 PK, 25 PK dan 40 PK. Mesin diesel yang umum digunakan adalah mesin Mitsubishi PS-100, PS-120, Yanmar TF 300, Hino 200 dan 300, Kubota serta Nissan 300.

\section{Kebutuhan Bahan Bakar Minyak Kapal Ikan}

Kapal perikanan di PPN Palabuhanratu menggunakan 2 jenis bahan bakar yakni solar dan bensin. Bahan bakar minyak jenis bensin yang biasa digunakan terdiri dari 2 (dua) macam yaitu pertalite dan premium. Menurut (Rahardjo et al. 2011) bensin adalah campuran kompleks yang terdiri dari senyawasenyawa 9 hidrokarbon (unsur utama), yang memiliki daerah didih sekitar $40^{\circ}-180^{\circ} \mathrm{C}$ yang dihasilkan dari beberapa proses. Bahan bakar ini sering juga disebut gasoline atau petrol. Jenis bensin premium adalah bahan bakar minyak jenis distalat berwarna kekuningan yang jernih. Warna kuning tersebut akibat adanya zat pewarna tambahan (dye). Sedangkan 'pertalite' menurut Pertamina (2021) adalah bahan bakar gasoline yang memiliki angka oktan 90, sebagai solusi perantara untuk konsumen yang saat ini menggunakan 'premium'. Selain bensin, nelayan juga menggunakan bahan bakar minyak jenis solar. Solar (diesel fuel) adalah fraksi minyak bumi yang mendidih pada $175^{\circ}-370^{\circ} \mathrm{C}$ dan merupakan bahan bakar jenis distalat berwarna kuning kecoklatan jernih. Umumnya minyak solar digunakan untuk bahan bakar pada semua jenis mesin diesel dengan putaran tinggi (di atas $1.000 \mathrm{rpm}$ ) (Rahardjo et al. 2011). Oleh sebab itu nelayan dengan kapal mesin diesel membutuhkan BBM jenis solar.

Kebutuhan BBM pada kapal perikanan tidak hanya untuk menjalankan mesin utama melainkan mesin bantu seperti penerangan dan penyimpanan ikan. Setiap kapal ikan dengan alat tangkap yang berbeda memiliki kebutuhan BBM yang berbeda pula. Hasil perhitungan kebutuhan BBM untuk masing-masing alat tangkap dalam setiap bulannya dapat dilihat pada Gambar 1 dan 2.

Pihak PPN Palabuhanratu dalam memenuhi BBM kapal perikanan menyediakan dua pengisian solar yang berada di dalam komplek Pelabuhan. Jenis solar yang dijual masing-masing penyalur berbeda, pada SPDN 39.43118 yang dikelola KUD Mina Mandiri Sinar Laut menjual solar bersubsidi sedangkan SPBUN 38.43104 yang dikelola PT. Mekar Tunas Raya Sejati menjual solar non-subsidi atau industri. Perbedaan antar kedua jenis solar tersebut adalah harga dan letak dalam komplek pelabuhan. SPDN yang menjual solar subsidi terletak di dermaga 1 dengan mayoritas kapal berukuran 1-30 GT. Sedangkan SPBN yang menjual solar industri terletak di dermaga 2 dengan mayoritas kapal berukuran $>30$ GT. Dalam memenuhi kebutuhan BBM, nelayan membeli solar pada tempat yang telah disediakan pihak pelabuhan. Namun tetap ada nelayan yang membeli solar ke SPBU seperti nelayan kapal angkutan bagan. Kebutuhan BBM pada masing-masing alat tangkap dominan di PPN Palabuhanratu secara rinci dapat dilihat di bawah ini. 


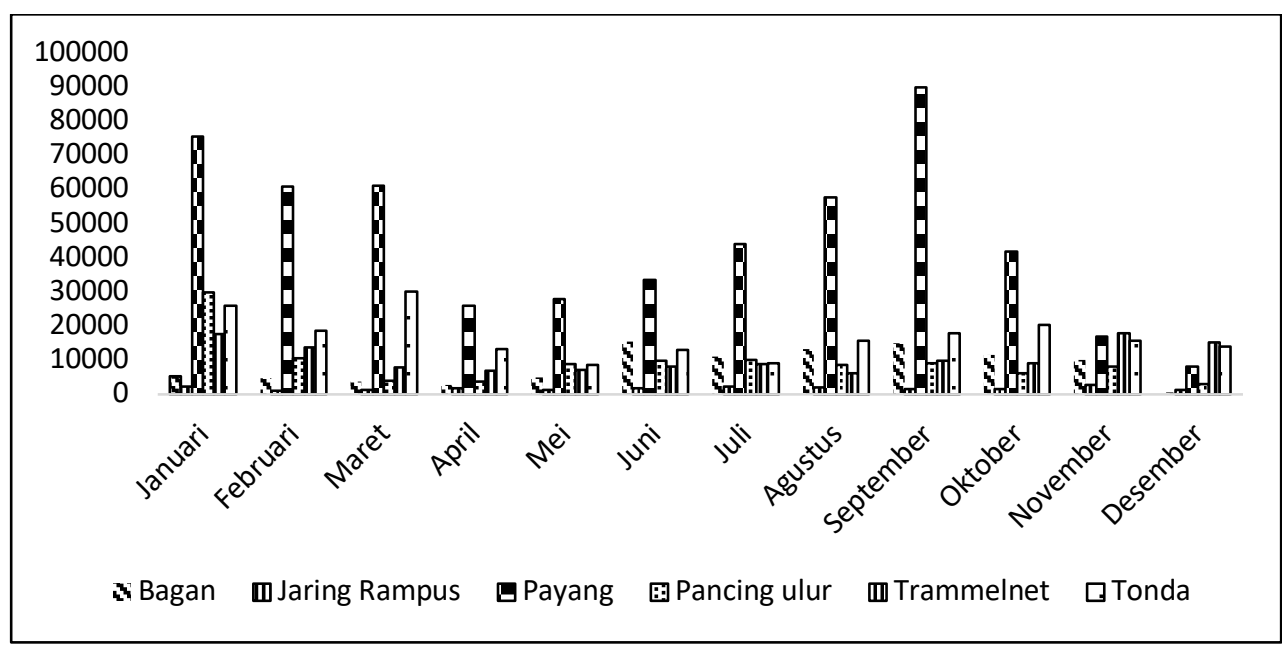

Gambar 1 Kebutuhan BBM alat tangkap bagan, jaring rampus, payang, pancing ulur, trammel net, dan pancing tonda

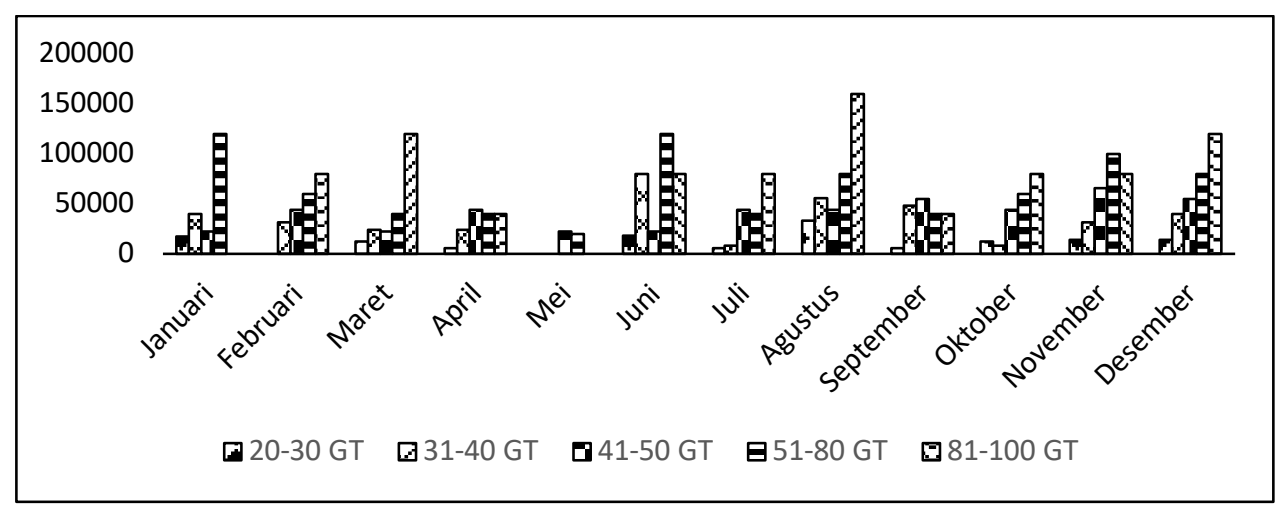

Gambar 2 Kebutuhan BBM pada kapal longline

\section{Kapal Angkutan Bagan}

Kapal angkutan bagan merupakan kapal yang beroperasi untuk mengangkut hasil tangkapan dari alat tangkap bagan. Salah satu kapal angkutan bagan dalam penelitian ini bernama KM. Saraswati yang memiliki catatan lengkap konsumsi BBM selama satu tahun belakang. Sehingga perhitungan kebutuhan BBM dapat diolah berdasarkan data tersebut. Kapal dan mesin KM. Saraswati memiliki umur teknis yang sama yakni enam tahun dengan dimensi kapal panjang 15 meter, lebar 4 meter dan dalam 2,5 meter. Jumlah kapal angkutan bagan dari hasil wawancara didapatkan bahwa 21 kapal bermesin Mitsubishi PS-100 dan 2 kapal yaitu KM. Elang Samudera 1 dan KM. Elang Samudera 3 bermesin PS-120. Kapasitas tangki dalam kapal 120 liter, tangki yang digunakan yaitu jerigen berwarna biru dengan kapasitas 30 liter. Kapal bagan menggunakan bahan bakar minyak jenis solar yang biasanya dibeli oleh masing-masing pengurus kapal.

Trip kapal bagan umumnya tidak penuh satu bulan, melainkan sekitar 25 hari. Lima hari untuk libur saat terang bulan dan bergantung pada keadaan ikan, jika ikan yang tertangkap banyak biasanya nelayan bagan tidak ada libur dalam sebulan. Pengurus kapal terbiasa membeli solar di SPBU Palabuhanratu yang berada di luar komplek pelabuhan, padahal sudah tersedia SPDN dalam PPN Palabuhanratu. Menurut keterangan petugas SPBU, para pengurus kapal bagan mengisi bahan bakar minyak jenis solar pada pagi hari. Hasil wawancara dengan pemilik kapal bagan menerangkan bahwa pengurus kapal juga sering membeli solar pada pengecer. Hal ini dikarenakan solar pada SPBU habis dan pengurus terpaksa membeli pada pengecer. Selain itu, pemilik kapal tidak dapat menunda keberangkatan kapal hanya untuk menunggu solar. Keputusan itu diambil oleh pemilik karena memikirkan nasib anak buah kapal (ABK) yang bekerja padanya dan menghindari keluhan dari ABK. Pemilik kapal angkutan bagan memutuskan tidak berangkat melaut hanya jika mengalami kerusakan mesin.

Keterangan nakhoda kapal Saraswati, kebutuhan solar dapat mencapai 120 liter per hari, hal ini terjadi karena kapal mengambil ikan yang jauh dari daerah biasanya. Rata-rata kecepatan saat keadaan 
steaming atau perjalanan menuju DPI adalah 7 mil/jam atau 7 knot. Daerah penangkapan ikan alat tangkap bagan saat musim puncak sekitar bulan Maret terdapat di Karanghawu, Cimaja, Cibangban, Cisolok dengan jarak 5-10 mil dan perjalanan sekitar 2 jam dan bulan Juli hingga November pada daerah Jampang Selatan. Hal ini sesuai dengan pernyataan Ardi (2009) bahwa pola persebaran bagan di Teluk Palabuhanratu memiliki pola yang mengelompok baik yang di Kecamatan Cisolok, Kecamatan Palabuhanratu, dan Kecamatan Ciemas. Berbeda dengan musim paceklik atau saat bulan Desember - Februari yang umumnya nelayan bagan hanya melakukan trip 17 kali/bulan. Pada kapal Saraswati bulan Desember hingga Februari hanya melakukan 51 trip dan menghabiskan solar 1.500 liter. Hasil perhitungan dari data jumlah trip per bulan yang dihitung oleh pihak pelabuhan dikalikan dengan rata-rata konsumsi BBM KM. Saraswati dapat dilihat pada Gambar 1. Kapal angkutan bagan melakukan trip selama satu hari dengan membawa solar sebanyak 29-51 liter. Kebutuhan solar terbanyak terjadi pada bulan Juni sebesar 15.351 liter Kebutuhan solar terendah terjadi pada bulan Desember dimana hanya 551 liter solar. Total solar yang dibutuhkan nelayan bagan dalam setahun adalah 98.611 liter.

\section{Kapal Payang}

Armada kapal payang di PPN Palabuhanratu menurut data kapal tahun 2020 sebanyak 44 unit. Seluruh kapal payang tersebut terbuat dari bahan kayu. Mesin yang digunakan adalah mesin tempel dengan merek Yamaha. Terdapat 2 jenis mesin tempel yang digunakan, namun sebanyak 93\% menggunakan mesin 40 PK dan sisanya 25 PK. Daerah penangkapan ikan (DPI) atau fishing ground potensial hasil overlay data lapangan dan data klorofil-a citra modis ikan tongkol (Euthynnus sp.) pada alat tangkap payang di perairan Palabuhanratu menurut Mujib et al. (2013) antara lain adalah Cimandiri, Tanjung Kembar, Gedogan, Ujung Karangbentang, Ujung Sodongprapat, dan Teluk Amuran. Dimensi ukuran kapal payang umumnya memiliki panjang 11 meter, lebar 1,5 meter dan dalam 1 meter. Bahan bakar minyak yang digunakan kapal ini berjenis bensin. Dalam keadaan normal, kapal payang dalam satu kali trip membutuhkan bensin sekitar 84 liter.

Pada musim paceklik atau sulit mendapatkan ikan membutuhkan bensin dengan jumlah yang lebih banyak yaitu dapat mencapai 108 liter/trip. Sedangkan pada musim puncak rata-rata dibutuhkan bensin per trip lebih sedikit dari keadaan normal yakni 66 liter. Kebutuhan bensin kapal payang setiap bulannya mengalami fluktuasi. Bulan Desember menjadi bulan dengan kebutuhan bensin paling sedikit untuk kapal payang yaitu sebesar 8.208 liter bensin, hal ini dikarenakan jumlah trip yang mengalami penurunan drastis. Sedangkan kapal payang pada bulan September membutuhkan bensin terbanyak dari bulan lainnya yaitu 89.856, hal ini disebabkan oleh trip pada bulan Agustus dan September mengalami peningkatan. Total kebutuhan bensin kapal payang dalam setahun adalah 54.3110 liter.

\section{Kapal Jaring Rampus}

Kapal dengan alat tangkap jaring rampus umumnya menggunakan mesin tempel Yamaha 5,5 PK, 6,5 PK, dan 8,5 PK. Nelayan biasa menyebut mesin tingting atau gantar. Bahan bakar yang digunakan yaitu bensin 'pertalite' dan sebagian kecil bensin 'premium'. Nelayan umumnya membeli bensin tersebut di SPBU setempat. Trip kapal terbanyak pada bulan Juli yaitu 285 trip dan terendah pada bulan Februari sebanyak 99 trip. Perbedaan jumlah trip mempengaruhi jumlah kebutuhan BBM pada tiap bulannya. Jumlah kebutuhan BBM terbesar pada bulan Juli sebesar 2.280 liter bensin dan terendah pada bulan Februari yaitu sebesar 990 liter bensin. Hasil tangkapan dominan jaring rampus ialah ikan Swangi. Kondisi operasi penangkapan ikan swanggi dalam kurun waktu lima tahun mulai dari tahun 2004 sampai dengan 2008, puncak musimnya terjadi pada bulan Januari, Februari, Juni dan Juli (Sulistiawan dan Diatri 2012). Terdapat kesesuaian dalam puncak kebutuhan BBM pada bulan Januari, Juni dan Juli yakni sebanyak 2.350 liter, 1.696 liter, dan 2.280 liter bensin. Berdasarkan hasil perhitungan, kebutuhan BBM tahunan kapal jaring rampus sebesar 21.144 liter bensin.

\section{Kapal Trammel net}

Armada penangkapan dengan alat tangkap trammel net pada umumnya menggunakan mesin yang biasa disebut nelayan mesin diesel dompleng. Mesin tersebut bermerek Yanmar TF 300 atau Kubota. Jenis bahan bakar minyak yang digunakan adalah solar. Umumnya nelayan melakukan trip selama satu hari dengan kebutuhan BBM sekali trip adalah 30-60 liter solar. Jumlah trip pada bulan September menjadi trip terbanyak di tahun 2020 yaitu sebesar 331 trip. Sedangkan jumlah trip terendah pada bulan Agustus 203 trip. Rata-rata kebutuhan BBM per kapal sebesar 30 liter solar. Kebutuhan BBM bulanan paling tinggi berada pada bulan Juli dengan jumlah kebutuhan 8.820 liter solar. Sedangkan bulan Agustus menjadi bulan dengan kebutuhan BBM terendah yaitu sebesar 6.090 liter solar. Total kebutuhan solar unit penangkapan 
trammel net adalah 128.760 liter solar selama satu tahun. Nelayan jaring tiga lapis ('jatilap') atau trammel net di Palabuhanratu lebih banyak mengoperasikan alat tangkap ini di dasar perairan dengan tujuan utama untuk menangkap udang, namun alat tangkap ini juga efektif manangkap jenis ikan lain (Hufiadi 2008). Menurut Nugraha et al. (2021) musim udang terjadi selama lima bulan yaitu bulan Juni, September, Oktober, November, dan Desember. Hal ini sesuai dengan hasil perhitungan kebutuhan BBM yang berjumlah besar pada bulan Juni, November, dan Desember. Jumlah trip dari kapal dengan alat tangkap trammel net meningkat pada bulan-bulan tersebut, sehingga kebutuhan BBM nelayan trammel net meningkat pula.

\section{Kapal Pancing Ulur}

Kapal dengan alat tangkap pancing ulur di PPN Palabuhanratu berukuran 1-2 GT. Bahan badan kapal dominan terbuat dari fiber dan hanya $2 \%$ dari populasi kapal yang terbuat dari bahan kayu. Dimensi kapal dengan ukuran panjang 5-11 meter, lebar 0,9-1,8 meter dan tinggi 0,7-0,9 meter. Ukuran kapal memengaruhi kekuatan mesin yang digunakan oleh kapal tersebut. Mesin pada kapal pancing ulur berkekuatan 5,5 PK, 9 PK dan 15 PK dengan merek yang umum digunakan adalah Yamaha dan Honda. Bahan bakar minyak yang digunalan adalah bensin dengan jenis premium atau pertalite. Kapal pancing ulur berjumlah 219 unit yang terdiri dari 51 unit kapal berkekuatan 15 PK, sebanyak 40 unit kapal berkekuatan 9 PK dan 219 unit kapal berkekuatan 5,5 PK. Alat tangkap pancing ulur dominan menangkap ikan layur di Teluk Palabuhanratu. Operasi penangkapan pancing ulur untuk menangkap ikan layur efektif pada bulan Oktober-Desember (Branenda et al. 2020). Namun hal tersebut tidak beriringan dengan kenaikan kebutuhan BBM pada bulan Oktober, November, dan Desember.

Kebutuhan bensin tertinggi pada bulan Januari yakni sebesar 29.820 liter dengan jumlah trip sebanyak 2.485 dimana terjadi kenaikan yang signifikan pada jumlah trip. Sedangkan hasil perhitungan terendah terjadi pada bulan April yakni sebanyak 3.840 liter bensin. Kenaikan kebutuhan BBM pada bulan Januari sesuai dengan pernyataan Sulistiawan dan Diatri (2012) bahwa kondisi operasi penangkapan ikan layur dalam kurun waktu lima tahun mulai dari tahun 2004 sampai dengan 2008, puncak musimnya terjadi pada bulan Januari, Februari, April, Agustus, dan Desember. Namun tidak sesuai dengan hasil kebutuhan BBM pada bulan April yang menurun. Total kebutuhan BBM kapal pancing ulur dalam satu tahun adalah sebanyak 111.948 liter bensin.

\section{Kapal Tonda}

Kapal pancing tonda yang ditemui di PPN Palabuhanratu umumnya memiliki 2 mesin penggerak. Mesin yang umum digunakan adalah Jiandong dengan kekuatan sekitar 30 PK dengan bahan bakar solar. Sedangkan untuk kebutuhan listrik menggunakan panel surya. Kapal tonda terbuat dari bahan kayu dengan dimensi panjang kapal 17 meter, lebar 4 meter, dan dalam 3 meter. Pemilik kapal tonda memiliki pegawai di darat untuk mengurus perbekalan dan logistik, dan anak buah kapal (ABK) melaut selama lebih kurang 15 hari. Kebutuhan solar kapal tonda yang melakukan trip selama 15 hari adalah 360-500 liter solar. Umumnya pengurus kapal membeli kebutuhan solar di SPDN dengan jerigen yang selanjutnya diantar oleh kuli menuju kapal di dermaga 2. Hasil perhitungan kebutuhan BBM menurut jumlah keberangkatan kapal tonda sesuai SPB dikalikan jumlah kebutuhan per trip kapal dapat dilihat pada Gambar 1. Jumlah kebutuhan solar terbesar terdapat pada bulan Maret sebesar 30.000 liter solar. Sedangkan jumlah kebutuhan terendah pada bulan Mei yakni sebanyak 8.640 liter solar. Menurut keterangan nelayan, pada bulan Mei sebagian nelayan merayakan hari raya lebaran di rumah, sehingga berpengaruh pada jumlah trip kapal tonda yang memiliki waktu melaut selama 15 hari.

Kapal tonda umumnya memiliki daerah penangkapan di sekitar rumpon pada lintang 8-9 dengan jarak tempuh berkisar 130-150 mil. Nilai rata-rata trip kapal tonda per bulan adalah 38 trip. Kebutuhan tahunan kapal tonda terhadap solar subsidi berkisar 202.170 liter solar. Menurut Prayoga et al. (2017) tingginya hasil tangkapan pada musim peralihan 2 yakni September-November diduga disebabkan oleh kondisi cuaca yang cukup mendukung dalam melakukan penangkapan ikan tongkol sehingga para nelayan dapat melakukan penangkapan dengan optimal. Rendahnya hasil tangkapan pada musim barat yaitu bulan Desember sampai dengan bulan Februari, diduga pada saat musim barat cuaca sedang dalam kondisi yang buruk karena tingginya curah hujan yang menyebabkan para nelayan tidak bisa melakukan kegiatan penangkapan ikan dengan optimal. Hal ini mempengaruhi jumlah trip nelayan tiap bulannya, sehingga pembelian BBM berfluktuasi. 


\section{Kapal Longline}

Kapal longline diklasifikasikan berdasarkan ukuran gross tonnage (GT) kapal. Menurut Sa'id (2010) kapal dengan ukuran lebih besar akan membutuhkan bahan bakar lebih banyak untuk tiap mil jarak tempuhnya. Oleh sebab itu, pada penelitian ini kapal longline dibagi menjadi 5 kelompok sesuai ukuran gross tonnage, antara lain 21-30 GT, 31-40 GT, 41-50 GT, 51-80 GT dan 80-100 GT. Hal ini dilakukan agar perhitungan kebutuhan solar kapal longline memiliki keakuratan yang lebih tinggi. Pada umumnya kapal longline dengan kelompok 21-30 GT menggunakan mesin Hino 200 PK. Kelompok kapal pada ukuran 31-40 GT menggunakan mesin Hino 270 PK, 4 silinder. Kapal dengan ukuran 41-50 PK menggunakan mesin Hino Eka Japan, 6 silinder 125 CC. Mesin yang digunakan pada kelompok kapal 5180 PK salah satunya merk Nissan 275 CC, dengan 10 silinder. Kebutuhan solar kapal longline berdasarkan kelompok ukuran GT dapat dilihat pada Gambar 2.

Jumlah kebutuhan akan solar tiap bulannya mengalami fluktuasi tergantung pada jumlah trip kapal, ukuran tonase kapal yang melaut dan lama waktu trip. Perhitungan ini dilakukan sesuai dengan jumlah kebutuhan solar dalam satu kali trip yang umumnya selama 50-60 hari. Pada kapal longline yang melakukan trip dengan waktu lebih lama akan dikirimkan BBM oleh kapal pengirim logistik. Kebutuhan solar kapal longline $\leq 30$ GT disuplai oleh solar subsidi sedangkan kapal longline $>30$ GT oleh solar industri. Kapal longline ukuran 21-30 GT membutuhkan solar subsidi terbanyak pada bulan Agustus sebesar 33.000 liter dengan jumlah trip 11. Jumlah kebutuhan solar industri terbanyak untuk kapal 31-40 GT pada bulan Juni sebesar 560.000 liter. Kapal dengan ukuran 41-50 GT membutuhkan solar terbanyak pada bulan November sebesar 66.000 liter. Ukuran kapal longline sebesar 51-80 GT memiliki kebutuhan kapal paling banyak pada bulan Januari sebesar 120.000 liter. Kelompok kapal terbesar yakni 81-100 GT membutuhkan solar paling banyak pada bulan Agustus sebesar 160.000 liter. Jumlah kebutuhan tahunan solar subsidi untuk kapal longline sebayak 138.500 liter dan pada kapal longline ukuran >30 GT sebanyak 290.000 liter solar non-subsidi.

\section{Penyalur BBM Resmi PPN Palabuhanratu}

\section{Solar Packed Dealer Nelayan (SPDN)}

SPDN merupakan tempat pengisian solar khusus nelayan yang terletak di darat dan bahan bakar dipompa ke jerigen untuk dibawa ke perahu nelayan (Iswandi dan Kurniawati 2020). Kebutuhan solar bagi nelayan di PPN Palabuhanratu salah satunya disuplai oleh Koperasi Unit Desa (KUD) Mina Mandiri Sinar Laut dengan bentuk penyalur SPDN 39.43118 yang terdaftar sebagai penyalur BBM badan usaha niaga migas untuk kegiatan usaha niaga umum BBM. Waktu pelayanan pengisian solar dimulai pukul 07.0016.00 atau tutup lebih cepat sesuai dengan jumlah permintaan nelayan. Jumlah pengisian solar terbanyak mencapai 6 ton dalam sehari. Jumlah kapal yang mengisi solar dalam sehari paling banyak 8-10 kapal saat musim penangkapan puncak. Saat musim barat atau gelombang tinggi kapal yang mengisi sekitar 2-3 kapal dalam sehari atau bahkan tidak ada. Nelayan umumnya mengisi 10 jerigen ( 1 jerigen berkapasitas 30 liter) dan paling banyak 60 jerigen untuk satu kapal. Tidak hanya kapal di dermaga 1 yang mengisi solar di SPDN tersebut, namun kapal-kapal di dermaga 2 juga. Cara pengisian solar menggunakan gerobak yang berisi maksimal 15 jerigen sesuai kebutuhan kapal. Selanjutnya gerobak diantarkan oleh kuli dengan upah Rp1.000 per jerigen. Kapal yang menggunakan jasa tersebut dominan jenis kapal tonda dan kapal longline $\leq 30$ GT.

Tangki penampungan atau disebut tangki tegak yang dimiliki SPDN mampu menampung lebih kurang 120 kilo liter (KL) solar. Pengisian tangki dilakukan sesuai dengan permintaan petugas SPDN. Tangki diisi dengan mobil tangki pertamina berkapasitas $16 \mathrm{KL}$. Pengisian kembali tangki BBM milik KUD tidak selalu sama tiap bulannya. Pada bulan tertentu memerlukan suplai solar lebih banyak dan bulan lainnya lebih sedikit. Hal ini dipengaruhi oleh jumlah kapal yang melakukan operasi penangkapan. Pada saat keadaan laut memungkinkan untuk melakukan operasi penangkapan, maka jumlah kebutuhan solar meningkat. Suplai solar dari mobil tangki pertamina berukuran 16 KL ke tangki KUD saat jumlah trip kapal meningkat umumnya hanya mencukupi kebutuhan selama 2-5 hari. Sedangkan saat keadaan laut mengalami gelombang dan arus kencang suplai solar $16 \mathrm{KL}$ mampu mencukupi kebutuhan selama 7-10 hari bahkan 14 hari. Menurut hasil perhitungan, bulan dengan jumlah kebutuhan solar subsidi tertinggi pada bulan Agustus sebesar 68.046 liter. Kebutuhan terendah terjadi pada bulan Mei sebesar 20.832 liter.

\section{Stasiun Pengisian Bahan Bakar Nelayan (SPBN)}

Stasiun Pengisian Bahan Bakar Nelayan (SPBN) adalah stasiun bahan bakar yang khusus menjual solar bagi nelayan. SPBN terletak di daerah yang dekat dengan sentra aktivitas nelayan. Setiap SPBN 
memiliki kelengkapan seperti tangki BBM, pompa BBM, dan gedung kantor. Perbedaan antara SPBN dan Solar Packed Dealer Nelayan (SPDN) adalah lokasinya. SPBN terletak di pinggir laut/di tengah laut agar perahu dapat bersandar untuk mengisi bahan bakar (Iswandi dan Kurniawati 2020). Kebutuhan solar untuk kapal di atas 30 GT di PPN Palabuhanratu disuplai oleh SPBUN 38.43104 yang dikelola PT. Mekar Tunas Raya Sejati. Jenis solar yang dijual merupakan solar non-subsidi atau industri. Perbedaan dengan solar subsidi tentu harga dan sumber solar tersebut. Harga solar industri bergantung pada nilai dolar saat itu, hal ini dikarenakan solar yang digunakan berasal dari luar negeri yakni Singapura. Transaksi antara pembeli atau pengurus kapal dengan pihak SPBN melalui transaksi non-tunai atau transfer. Petugas pengisi solar tidak menerima transaksi tunai dan hanya bertugas sebagai pengisi solar. Menurut keterangan petugas pengisi solar suplai dari sumber solar dalam sebulan dapat mencapai 200.000 liter solar. Pengisian solar ke kapal ikan dalam sehari dapat mencapai 50.000 liter. Perhitungan kebutuhan solar industri menurut data laporan SPB kapal longline dengan hasil wawancara kebutuhan solar industri dapat dilihat pada Gambar 2. Kebutuhan solar non-subsidi terbanyak pada bulan Agustus sebesar 340.000 dan terendah pada bulan Mei sebesar 42.000. Total kebutuhan solar non-subsidi dalam setahun adalah 2.556.000 liter.

Kebutuhan BBM di PPN Palabuhanratu Kebutuhan BBM per tahun jenis solar industri paling tinggi sebesar 2.556.000 liter dengan konsumsi terbanyak dari kapal longline 81-100 GT sebesar 880.000 liter dan terendah kapal longline berukuran 31-40 GT sebesar 392.000 liter. Selanjutnya kebutuhan solar subsidi untuk kapal $\leq 30$ GT sebanyak 568.041 liter dengan konsumsi terbanyak oleh kapal Tonda sebesar 202.170 liter dan terendah kapal bagan 98.611 liter. Bahan bakar minyak jenis bensin dalam setahun dibutuhkan sebanyak 676.202 liter bensin, dengan konsumsi tertinggi dari kapal payang sebesar 543.110 liter dan terendah oleh kapal jaring rampus sebesar 21.144 liter dalam setahun.

Perhitungan dari total jumlah kebutuhan solar subsidi setiap bulannya dengan suplai solar subsidi dari pertamina oleh mobil tangki kapasitas $16 \mathrm{KL}$ dapat dilihat pada Tabel 1. Pada bulan November dibutuhkan suplai solar subsidi terbanyak yaitu 4 kali oleh mobil tangki pertamina kapasitas $16 \mathrm{KL}$, dan bulan Mei dibutuhkan penyuplaian solar paling sedikit yaitu 1-2 kali oleh mobil tangki pertamina kapasitas 16 KL. Rata-rata dalam sebulan dibutuhkan pemasok mobil tangki 16 KL sebanyak 3 kali. Total kebutuhan suplai mobil tangki ukuran $16 \mathrm{KL}$ adalah 33 kali dalam setahun.

Kebutuhan terhadap solar industri tiap bulannya dipasok oleh mobil tangki berkapasitas $16 \mathrm{KL}$ dan $8 \mathrm{KL}$. Perhitungan jumlah suplai mobil tangki terhadap jumlah solar industri tiap bulannya dapat dilihat pada Tabel 1. Kebutuhan pemasokan mobil tangki terbanyak pada bulan Agustus sebesar 21-22 kali. Sedangkan kebutuhan pemasokan oleh mobil tangki terendah pada bulan Mei sebanyak 2-3 kali. Rata-rata suplai solar industri yang dibutuhkan dari mobil tangki pertamina kapasitas $16 \mathrm{KL}$ adalah 13-14 kali per bulan. Total kebutuhan suplai mobil tangki ukuran $16 \mathrm{KL}$ sebesar 160 kali dalam setahun. Bahan bakar jenis bensin juga dibutuhkan bagi kapal penangkap ikan di PPN Palabuhanratu, meskipun tidak tersedianya penjual bensin di dalam komplek pelabuhan. Hasil perhitungan dibutuhkan BBM jenis bensin sebanyak 676.202 liter dalam setahun. Rata-rata kebutuhan dalam sebulan sebanyak 56.350 liter. Pengisian bensin dari SPBU kepada nelayan dilakukan dengan menggunakan jerigen berkapasitas 30 liter. Berdasarkan hasil penelitian kapal perikanan di PPN Palabuhanratu membutuhkan 3 jenis BBM, antara lain solar industri, solar subsidi dan bensin. Kebutuhan akan 3 jenis BBM disuplai oleh SPDN, SPBN, dan SPBU sekitar Pelabuhan.

Jumlah presentasi dengan ketiga jenis BBM tersebut dapat dilihat pada Gambar 3. Berdasarkan hasil perhitungan, diketahui bahwa jumlah kebutuhan terhadap solar subsidi paling rendah yakni sebesar $15 \%$. Selanjutnya kebutuhan terhadap bensin sebesar $18 \%$ dan tertinggi pada solar industri sebesar $67 \%$ atau dominan. Selisih penggunaan solar industri dengan solar subsidi adalah $52 \%$, hal ini terjadi karena kapal yang menggunakan solar industri berukuran $>30$ GT. Menurut Sa'id (2010) kapal dengan ukuran lebih besar akan membutuhkan bahan bakar lebih banyak untuk tiap mil jarak tempuhnya. 


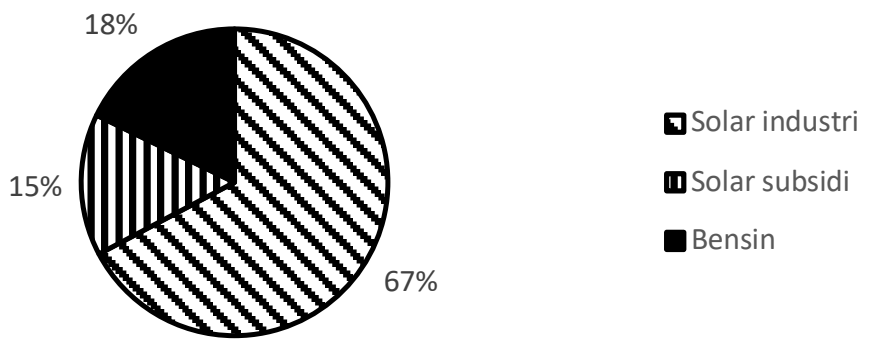

Gambar 3 Kebutuhan jenis BBM di PPN Palabuhanratu

Tabel 1 Kebutuhan BBM setiap bulan di PPN Palabuhanratu

\begin{tabular}{|c|c|c|c|c|c|c|}
\hline \multirow[b]{2}{*}{ Bulan } & \multicolumn{3}{|c|}{ Jumlah BBM (liter) } & \multicolumn{3}{|c|}{$\begin{array}{l}\text { Banyaknya Suplai (mobil tangki kapasitas } \\
16 \text { KL untuk solar industri dan subsidi, } \\
\text { serta jerigen kapasitas } 30 \text { liter untuk bensin) }\end{array}$} \\
\hline & $\begin{array}{l}\text { Solar } \\
\text { industri }\end{array}$ & Solar subsidi & Bensin & $\begin{array}{l}\text { Solar } \\
\text { industri } \\
\text { (mobil } \\
\text { tangki) }\end{array}$ & $\begin{array}{c}\text { Solar subsidi } \\
\text { (mobil tangki) }\end{array}$ & $\begin{array}{l}\text { Bensin } \\
\text { (jerigen) }\end{array}$ \\
\hline Januari & 182.000 & 66.567 & 107.554 & 11,38 & 3,63 & 3.585 \\
\hline Februari & 216.000 & 37.130 & 72.414 & 13,50 & 2,05 & 2.414 \\
\hline Maret & 206.000 & 53.802 & 66.468 & 12,88 & 3,12 & 2.216 \\
\hline April & 148.000 & 28.796 & 31.528 & 9,25 & 1,77 & 1.051 \\
\hline Mei & 42.000 & 20.832 & 38.236 & 2,63 & 1,23 & 1.275 \\
\hline Juni & 302.000 & 54.441 & 45.016 & 18,88 & 3,22 & 1.501 \\
\hline Juli & 172.000 & 34.908 & 56.238 & 10,75 & 2,18 & 1.875 \\
\hline Agustus & 340.000 & 68.046 & 68.430 & 21,25 & 4,03 & 2.281 \\
\hline September & 183.000 & 48.970 & 100.484 & 11,44 & 2,65 & 3.349 \\
\hline Oktober & 192.000 & 53.066 & 49.522 & 12,00 & 3,35 & 1.651 \\
\hline Nopember & 278.000 & 57.812 & 27.736 & 17,38 & 3,37 & 925 \\
\hline Desember & 295.000 & 43.671 & 12.576 & 18,44 & 2,74 & 419 \\
\hline Total & 2.556 .000 & 568.041 & 676.202 & 160 & 33 & 22.540 \\
\hline Rata-Rata & 213.000 & 47.337 & 56.350 & 13 & 3 & 1.878 \\
\hline
\end{tabular}

\section{Rekomendasi Distribusi BBM}

Distribusi BBM dari pihak SPDN maupun SPBN kepada nelayan di PPN Palabuhanratu perlu diperbaiki agar nelayan lebih mudah dan cepat dalam mengakses BBM bersubsidi maupun non-subsidi. Berikut rekomendasi yang disarankan berdasarkan hasil penelitian.

1) Melakukan Penyederhanaan administasi nelayan agar mudah dalam mengakses BBM subsidi (satu identitas multifungsi). Menurut keterangan nelayan yang tidak membeli BBM di dalam komplek pelabuhan dikarenakan kesulitan dalam mengurus administrasi. Sedangkan nelayan yang membeli BBM di SPBU sekitar pelabuhan terkadang dipersulit karena tidak memiliki kartu nelayan atau surat rekomendasi. Proses pembuatan surat rekomendasi harus disetujui oleh kepala Pelabuhan atau SKPD provinsi/kabupaten Sukabumi dimana letaknya relatif jauh dari Palabuhanratu dan persyaratan lainnya yang banyak sehingga nelayan merasa sulit dalam membuatnya. Berdasarkan permasalahan tersebut, perlu adanya penyederhanaan administrasi dengan prosedur yang mudah dipahami serta transparan, dan pengadaan kartu identitas khusus nelayan yang mampu mempermudah nelayan dalam mengakses solar subsidi di SPDN/SPBU sesuai dengan kuota maksimal tiap bulannya yaitu $25 \mathrm{KL}$ per kapal (PERMENKP No. 13 Tahun 2015). Sehingga nelayan tidak memerlukan surat rekomendasi lagi untuk mendapatkan BBM subsidi, cukup dengan menunjukkan sebuah kartu identitas yang sudah mencakup berapa kuota yang diperbolehkan. Hal ini dapat memperkecil kemungkinan BBM subsidi disalahgunakan oleh pihak lain dan menghilangkan tuduhan sebagai penimbun kepada nelayan.

2) Menggunakan perhitungan hasil penelitian untuk referensi kuota bbm dan membuka informasi akses kuota ketersediaan bbm untuk sektor perikanan pada setiap SPDN/SPBU di sekitar PPN Palabuhanratu. 
Menurut Peraturan Presiden No 191 Tahun 2014 kuota subsidi BBM jenis solar sudah ditetapkan setiap wilayah kabupaten atau kota. Transparansi jumlah kuota BBM subsidi secara real time pada setiap lembaga penyalur diperlukan untuk memudahkan nelayan mengestimasi waktu pembelian yang disesuaikan dengan waktu keberangkatan. Sehingga nelayan tidak langsung membeli BBM secara berlebihan saat tangki tegak baru diisi oleh mobil tangki pertamina. Selama ini permasalahan tersebut menyebabkan tidak meratanya distribusi BBM subsidi ke masing-masing nelayan. Selain itu, nelayan PPN Palabuhanratu mengakses bensin subsidi dan solar subsidi di SPBU sekitar Pelabuhan dengan waktu mengantri sekitar 4-6 jam dan sering tidak mendapatkannya karena stok habis. Adanya keterbukaan mengenai informasi kuota BBM subsidi membuat nelayan tidak khawatir mengenai ketersediaan solar subsidi di SPBU/SPDN.

3) Membuat mekanisme terstruktur dan pengawasan ketat untuk pembelian BBM subsidi dan non-subsidi. Terbatasnya tempat BBM di atas kapal membuat kapal-kapal besar yang memiliki waktu trip panjang melakukan transhipment solar. Hal ini membuat perhitungan solar tiap kapalnya tidak akurat. Sehingga diperlukan adanya mekanisme seperti tujuan kapal berangkat untuk transhipment logistik atau penangkapan. Membuat kebijakan bagi kapal $>30$ GT melampirkan bukti fraktur pembelian BBM di $\mathrm{SPB}$, hal ini mampu megurangi kecurangan pembelian BBM subsidi. Di samping itu, dengan adanya lampiran fraktur dapat dihitung secara jelas berapa BBM yang dibawa kapal tersebut sehingga jelas pemanfaatannya. Selain itu, selama ini pembelian solar subsidi di SPDN menggunakan jerigen sehingga tidak diketahui dengan pasti bahwa solar tersebut dibawa ke kapal yang sesuai dengan data pembelian. Pengantaran jerigen yang dibawa oleh kuli diperlukan pengawas untuk memastikan jerigen sampai pada kapal yang sesuai. Hal ini mampu mengurangi kecurangan solar subsidi dijual kembali atau digunakan oleh pihak lain yang tidak diperuntukan.

\section{KESIMPULAN DAN SARAN}

Beberapa kesimpulan dari penelitian ini yaitu; (1) Nelayan PPN Palabuhanratu membutuhkan BBM jenis solar dan bensin. Kebutuhan solar subsidi dalam setahun yang dibutuhkan oleh kapal $\leq 30$ GT antara lain tonda, trammel net, angkutan bagan, dan longline sebanyak 568.041 liter. Kebutuhan solar industri dalam setahun untuk kapal longline sebanyak 2.556 .000 liter. Sedangkan BBM jenis bensin dalam setahun yang dibutuhkan oleh kapal jaring rampus, payang, dan pancing ulur sebanyak 676.202 liter. (2) Jenis BBM yang terdapat dalam komplek pelabuhan hanya jenis solar. Namun tersedia solar subsidi dan solar industri. Jumlah BBM yang dijual penyalur BBM sesuai dengan jumlah permintaan. Permintaan akan solar industri menjadi dominan di PPN Palabuhanratu. Jumlah permintaan solar subsidi dalam setahun sebanyak $15 \%$ atau 568.041 liter dan solar industri sebanyak 67\% atau 2.556.000 liter dari total permintaan BBM di PPN Palabuhanratu. (3) Pemasokan mobil tangki solar subsidi yang dibutuhkan 2-4 kali per bulan dengan kapasitas mobil tangki 16.000 liter. Dalam setahun dibutuhkan sebanyak 33 kali penyaluran. Sedangkan solar industri dibutuhkan 160 kali pemasokan oleh mobil tangki berukuran $16 \mathrm{KL}$ dengan pemasokan per bulan sebanyak 3-21 kali.

Pihak pelabuhan dan penyalur BBM perlu membuat mekanisme pembelian BBM oleh nelayan, sehingga suplai BBM dari pertamina tetap terkontrol dan mencukupi kebutuhan. Penelitian lebih lanjut tentang jumlah BBM diperlukan dengan metode studi kasus agar penelitian terfokus dan perhitungan lebih akurat.

\section{DAFTAR PUSTAKA}

Ariola MM. 2006. Principles and Methods of Research. 1st ed. Manila (PHI): Rex Book Store. Diakses pada: https://books.google.co.id/books?id=zRY6xxaeyOwC\&pg. [Diunduh 2 Nov 2020].

Ardi, S. A. H. 2009. Pola persebaran dan hasil tangkap bagan di Teluk Pelabuhan Ratu. [Skripsi]. Universitas Indonesia. Depok.

Branenda, W. P., Zulkarnain, Muninggar, R., Purwangka, F., Apriliani, M. A. 2020. Pola musim penangkapan ikan layur (Trichiurus spp) di Perairan Teluk Palabuhanratu, Sukabumi, Jawa Barat. ALBACORE 3(3): 297-310.

Ekaputra, M., Hamdani, H., Suryadi, I. B. B., Apriliani, I. M. 2019. Penentuan daerah penangkapan potensial ikan tongkol (Euthynnus sp.) berdasarkan citra satelit klorofil-a di Palabuhanratu, Jawa Barat. ALBACORE J. Penelit. Perikan. Laut 3(2): 169-178. 
Fikri. 2020. Sebelum fajar menyingsing BBM bersubsidi sudah habis di SPBU Palabuhanratu. Diakses pada: https://aksarajabar.pikiran-rakyat.com/jabar/pr-99776041/sebelum-fajar-menyingsing-bbmbersubsidisudah-habis-di-spbu-palabuhanratu. [Diunduh 2020 Sep 20].

Hallyzepta, D. 2012. Analisis Kebutuhan Solar Untuk Mendukung Operasional Kapal Pancing Tonda di PPN Palabuhanratu. [Skripsi]. IPB University. Bogor.

Hufiadi. 2008. Proporsi dan komposisi hasil tangkapan jaring tiga lapis (trammel net) di Pelabuhan Ratu. BAWAL 2(2): 69-74.

Iswandi, M. W. R., Kurniawati, H. A. 2020. Desain SPBN yang dilengkapi stasiun perbekalan nelayan apung untuk mendukung kegiatan perikanan tangkap di Provinsi NTT. J. Tek. ITS 9(2): 125-130.

Kartika, L., Nurhayati, A., Dewanti, L. P., Rizal, A. 2020. Kontribusi perikanan tangkap dalam mendukung perekonomian di Kabupaten Pangandaran. Syntax Idea 2(8): 429-445.

Kencana, M. R. 2020. Nelayan keluhkan sulitnya dapat BBM bersubsidi. Liputan 6 Rubrik Bisnis Ekonomi. Diakses pada: https://www.liputan6.com/bisnis/read/4335524/nelayan-keluhkan-sulitnyadapatbbm-bersubsidi. [Diunduh 2020 Sep 20].

Luhur, E. S., Sari, Y. D. 2012. Dampak subsidi solar terhadap keberlanjutan usaha perikanan tangkap di Bitung dan Pelabuhanratu. J. Sosek KP 7(2): 139-151.

Mujib, Z., Oesono, H., Fitri, A. D. P. 2013. Pemetaan sebaran ikan tongkol (Euthynnus sp.) dengan data klorofil-a citra modis pada alat tangkap payang (danishseine) di Perairan Teluk Palabuhanratu, Sukabumi, Jawa Barat. J. Fish. Resour. Util. Manag. Technol 2(3): 150- 160.

Nugraha, A., Wahyuningrum, P. I., Simbolon, D. 2021. Adaptasi musiman nelayan trammel net di Pelabuhan Perikanan Samudera Cilacap. J. Teknologi Perikanan dan Kelautan 11(1): 99-109.

Peraturan Menteri-Kelautan dan Perikanan (Permen-KP) Nomor 8 Tahun 2012 tentang Kepelabuhanan Perikanan.

Peraturan Menteri-Kelautan dan Perikanan (Permen-KP) Nomor 13 tahun 2015 tentang Petunjuk Pelaksanaan Penerbitan Surat Rekomendasi Pembelian Jenis Bahan Bakar Minyak Tertentu Untuk Usaha Perikanan Tangkap.

Peraturan Presiden (Perpres) Nomor 191 Tahun 2014 tentang Penyediaan, Pendistribusian dan Harga Jual Eceran Bahan Bakar Minyak.

Pertamina. 2021. Pertalite. Diakses pada: https://www.pertaminafuels.com/gasoline/pertalite. [Diunduh 08 Maret 2021].

PPN Palabuhanratu. 2020. Data Kapal Tahun 2020 PPN Palabuhanratu. 1hal.

Prayoga, I. M. S., Putra, I. D. N. N., Dirgayusa, I. G. N. P. 2017. Pengaruh sebaran konsentrasi klorofil-a berdasarkan citra satelit terhadap hasil tangkapan ikan tongkol (Euthynnus sp) di Perairan Bali. Journal of Marine and Aquatic Sciences. 3(1): 30-46.

Rahardjo, O., Budihardjo, Asikin, Z., Setiyobudi, N. 2011. Bahan Bakar Gas (CNG) Alternatif Pengganti BBM Kapal Perikanan. Semarang (ID): Balai Besar Pengembangan Penangkapan Ikan.

Sa'id SD. 2010. Analisis efisiensi pemakainan bahan bakar mesin induk kapal purse seiner di Pelabuhan Pendaratan Nusantara Pekalongan. Gema Teknol 16(2): 99-105.

Saptanto, S., Zamroni, A., Ramadhan, A., Wijaya, R. A. 2016. Analisis kebijakan dampak penyesuaian harga BBM bersubsidi untuk nelayan. J. Kebijak. Sosek KP 6(2): 85-95.

Shafira, F. S., Rizwan, Kandi, O. 2021. Analisis kebutuhan air bersih dan bahan bakar minyak dalam mendukung aktivitas penangkapan di Pangkalan Pendaratan Ikan Ujung Seurangga, Kabupaten Aceh Barat Daya. Jurnal Kelautan dan Perikanan Indonesia. 1(1): 10-23.

Sudrajat, S. M. N. I., Rosyid, A., Bambang, A. N. 2014. Analisis teknis dan finansial usaha penangkapan ikan layur (Trichiurus sp) dengan alat tangkap pancing ulur (Handline) di Pelabuhan Perikanan Nusantara Palabuhanratu Sukabumi. J. of Fisheries Resources Utilization Management Technology. 3(3): 141-149. 
Suherman, A., Kurohman, F., Jayanto, B. 2020. Kinerja Operasional Pelabuhan Perikanan Nusantara (PPN) Palabuhanratu, Sukabumi, Jawa Barat. Jurnal Perikanan dan Kelautan. 10(1): 87-101.

Sulistiawan, R. S. N., Diatri M. 2012. Studi tentang pola musim dan tingkat upaya penangkapan beberapa ikan demersal yang didaratkan di Palabuhanratu Kabupaten Sukabumi Jawa Barat. J. Agroscience 4(5): 40-53.

Wijaya, R. A., Saptanto, S. 2014. Persepsi dan strategi adaptasi nelayan teradap isu pencabutan subsidi BBM. J. Kebijak. Sosek KP 4(2): 185-196.

Undang-undang (UU) Nomor 45 Tahun 2009 tentang Perikanan. 